\title{
Paraneoplastic Lambert-Eaton syndrome in a patient with disseminated metastatic cancer
}

\author{
Síndrome paraneoplásico de Lambert-Eaton en paciente con cáncer metastásico \\ diseminado
}

\author{
Gregorio Arellano-Aguilar', Erik Santiago Núñez-Mojica², José Luis Gutiérrez-Velazco² and \\ Luis Gerardo Domínguez-Carrillo ${ }^{3 *}$ \\ ${ }^{1}$ Medicine Division; ${ }^{2}$ Undergraduate Intern. Hospital Ángeles León; ${ }^{3}$ Rehabilitation Medicine, Faculty of Medicine, Universidad de Guanajuato. León, \\ Gto., Mexico
}

\begin{abstract}
Background: Neurological paraneoplastic syndromes are rare, occur in $0.01 \%$ of all cancer patients; like part of them, the Lambert-Eaton syndrome is an autoimmune presynaptic disorder of neuromuscular transmission characterized by muscle weakness and neurovegetative dysfunction, and often associated with small cell lung cancer. Case report: $A 72$ years old female with a family history of lung cancer and leukemia, with 7 months of dry cough and 3 months with waist and pelvic muscle weakness, oropharyngeal dysphagia, dry mouth, chronic constipation and weight loss of $10 \mathrm{~kg}$. Physical examination: patient prostrated; clinical muscle examination: pelvic muscles waist $-3 / 5$ and $-4 / 5$ the rest; diminished reflexes. Laboratory normal parathormone and hypercalcemia. With electrophysiological study and positive anti-voltage-gated calcium channel antibodies, confirming Lambert-Eaton syndrome and imaging studies with neoplastic condition in brain, liver and kidney, with unspecified primary origin.
\end{abstract}

KEY WORDS: Paraneoplastic neurologic syndrome. Lambert-Eaton syndrome.

\section{Resumen}

Antecedentes: Los síndromes paraneoplásicos neurológicos son poco frecuentes; se presentan en el $0.01 \%$ de todos los pacientes con cáncer. Uno de ellos es el síndrome de Lambert-Eaton, correspondiendo a un trastorno presináptico autoinmunitario de transmisión neuromuscular caracterizado por debilidad muscular y disfunción neurovegetativa, y asociado con frecuencia al carcinoma microcítico de pulmón. Caso clínico: Mujer de 72 años, con antecedentes heredofamiliares de cáncer de pulmón y leucemia, con tos seca de 7 meses, 3 meses con debilidad de los músculos de cintura pélvica, disfagia al inicio de la deglución, xerostomía, estreñimiento crónico y pérdida de peso de 10kg. Ala exploración física: paciente postrada; examen clínico muscular: músculos de cintura pélvica en $-3 / 5$, resto en -4/5; reflejos disminuidos. Pruebas de laboratorio indicando hipercalcemia y paratohormona normal. Estudio electrofisiológico y anticuerpos anticanales de calcio positivos, demostrando síndrome de Lamber-Eaton, y estudios de imagen con afectación neoplásica en cerebro, hígado y riñón, sin lograr especificar el origen primario.

PALABRAS CLAVE: Síndrome neurológico paraneoplásico. Síndrome de Lambert-Eaton.

\footnotetext{
Correspondence:

*Luis Gerardo Domínguez Carrillo

Calzada de Los Paraísos, 701

Col. Los Paraísos

C.P. 37320, León, Gto., México

E-mail: Igdominguez@ hotmail.com
}

Date of reception: 30-09-2016

Date of acceptance: 12-02-2018

DOI: 10.24875/CIRUE.M18000011
Cir Cir. 2018:86:72-76

Contents available at PubMed www.cirugiaycirujanos.com 


\section{Introduction}

Paraneoplastic neurological syndromes (PNS) are rare; they occur in $0.01 \%$ of all cancer patients. The first description of PNS goes back to 1890, by French physician M. Auche ${ }^{1}$. It occurs associated with cancer, but is not caused by direct tumor invasion, by metastasis or as a consequence of treatment. PNS can affect any area of the nervous system, either the central, peripheral or autonomic nervous system, and can precede or follow a cancer diagnosis. Sometimes, primary cancer is not found, not even at autopsy. $\mathrm{PNS}^{2}$ have an autoimmune etiopathogenesis, since when the body tries to eliminate the tumor cells it launches an immune response mediated by antibodies or by T-cells. Antibodies react with accessible membranes, directly being the cause of the disease, as in the cases of acetylcholine receptors in myasthenia gravis, or in voltage-gated calcium channels, as in Lambert-Eaton syndrome (LES). Cancer can be asymptomatic at the time of PNS presentation ${ }^{3}$. Some paraneoplastic antibodies are specifically associated with cancer and some are not. The exact incidence and prevalence of PNS is unknown; it has been estimated that $0.5-1 \%$ of all cancer patients have clinically detected PNS ${ }^{4}$. When PNS affects the neuromuscular junction, the most common neurological syndrome is myasthenia gravis, which is associated in $15 \%$ of patients with thymoma, followed in frequency by LES, which affects $3 \%$ of patients with small cell lung cancer.

When a patient showed up in whom the diagnosis of LES was established, we carried out this communication.

\section{Clinical case}

We present the case of a 72-year-old woman, homemaker, native to and resident of León, Guanajuato, with a relevant family history: mother deceased due to lung cancer, a brother with leukemia without the type being specified, and a son with ankylosing spondylitis. She had had hypertension for more than 10 years, controlled with angiotensin-converting enzyme inhibitors. She had had four gestations with four deliveries. Chief complaint with 7 months of evolution, characterized by dry cough; 3 months later, there was also fatigue and weakness, mainly in waist and pelvic muscles, which changed into generalized weakness over the preceding 2 months; she also experienced dysphagia at the beginning of swallowing, in addition to dry mouth and chronic constipation, with evacuation every 4 days. She also reported weight loss of $10 \mathrm{~kg}$ over the previous 4 months, attributed to dysphagia, and anhedonia. Progressive weakness had led to prostration; in addition, she required help to rise from a chair, and she was able to walk at home with +++help. On physical examination: blood pressure 110/70 mmHg; heart rate $106 \mathrm{bpm}$; respiratory rate 22 breaths per minute; temperature $36.8^{\circ} \mathrm{C} ; \mathrm{SaO}_{2} 89 \%$. Prostrate patient with non-evaluable gait, alert with disorientation in time, slowness in information processing; normal cranial nerves, eyes with normal fundus. Chest: symmetrical, with presence of intercostal retractions, decreased respiratory movements; respiratory sounds with normal vesicular murmur, rhythmic heart sounds, soft abdomen without visceromegalies. Clinical muscle examination: pelvic and scapular waist muscles at $-3 / 5$, the rest at $-4 / 5$, decreased osteotendinous reflexes; normal pulses and capillary refill. She was hospitalized for diagnostic workup, with laboratory tests showing: hemoglobin at $10.2 \mathrm{~g} / \mathrm{dL}$; hematocrit at $32.1 \%$; leukocytosis, $14,700 / \mu \mathrm{L}$; neutrophils, $81 \%$; erythrocyte sedimentation rate, $33 \mathrm{~mm} / \mathrm{h}$; platelets,

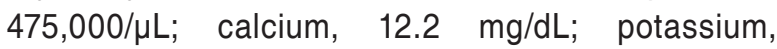
$5.7 \mathrm{mmol} / \mathrm{L}$; total protein, $5.7 \mathrm{~g} / \mathrm{dL}$; albumin, $2.5 \mathrm{~g} / \mathrm{dL}$; globulin, $3.2 \mathrm{~g} / \mathrm{dL}$; albumin-corrected calcium, $13.6 \mathrm{mg} / \mathrm{dL}$; normal bilirubin levels; alkaline phosphatase, $188 \mathrm{U} / \mathrm{L}$; lactate dehydrogenase, $684 \mathrm{U} / \mathrm{L}$; glucose, $178 \mathrm{mg} / \mathrm{dL}$; urea, $68.5 \mathrm{mg} / \mathrm{dL}$; creatinine, $1.2 \mathrm{mg} / \mathrm{dL}$; creatine phosphokinase, $25 \mathrm{U} / \mathrm{L}$; intact parathyroid hormone, $38.8 \mathrm{pg} / \mathrm{mL}$; urinalysis: $\mathrm{pH} 5$, hemoglobin ++ , nitrite-positive, WBCs $>100$, RBCs 2-4 and abundant bacteria. With the above data, urinary tract infection, hyperglycemia, hypercalcemia, grade II normocytic normochromic anemia, possible malignancy of localization to be determined, and probable LES diagnoses were established. Magnetic resonance imaging of the skull and chest and abdomen tomography (Figs. 1 to 3), revealed multiple metastatic infiltrations (without the origin being specified). Single-fiber electromyography results confirmed the neuromuscular junction alteration. A repetitive nerve stimulation test was therefore carried out, which showed, with low frequency stimulation, a response of potentials' increasing amplitude, which were increased with high frequency stimulation, electrophysiologically corroborating the presence of LES. When the diagnoses were discussed with the patient and her family, performing a gastrostomy for enteral feeding was proposed, as well as assessment by the oncology 


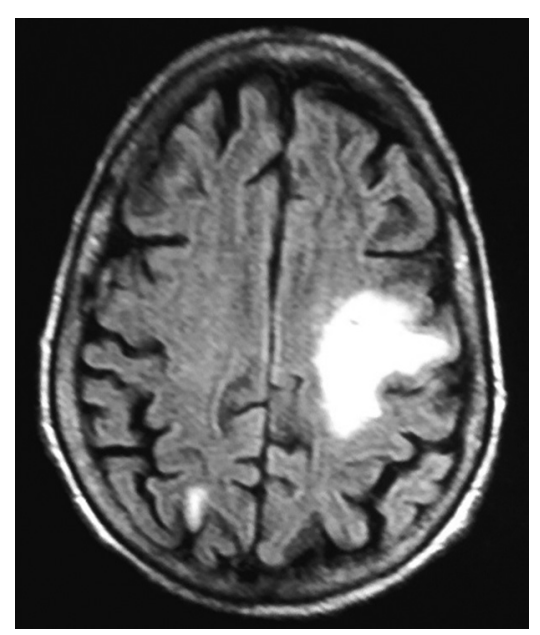

Figure 1. Magnetic resonance imaging of the skull, axial section, diffusely showing a larger amplitude of the subarachnoid space and extensive area of amorphous gliosis (Fasekas III), with confluent appearance, in the subcortical white substance of the left frontal lobe.

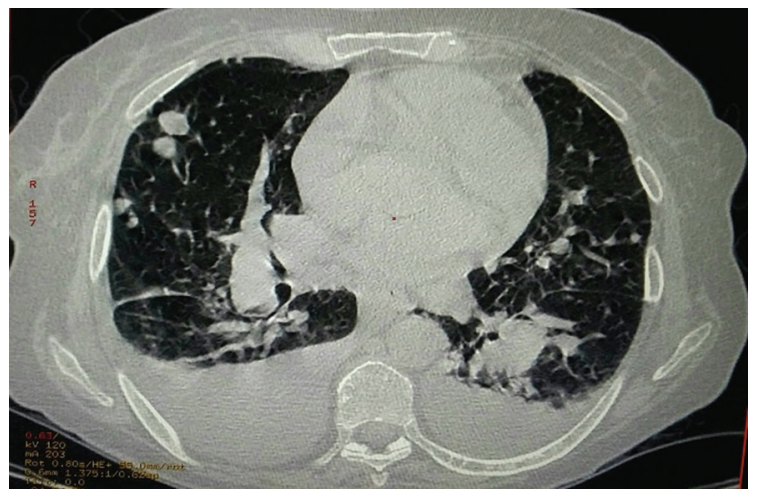

Figure 2. Chest tomography axial section image, showing randomly distributed nodular images, thickening of the bronchial walls with micronodular infiltrate and bilateral pleural effusion.

department and initial management with steroids. Treatment was started with gentamicin, with the urinary infection being controlled. The patient remained hospitalized for 12 days on treatment with 3,4-diaminopyridine phosphate at a dose of $15 \mathrm{mg}$ three times a day, prednisone at a dose of $10 \mathrm{mg} / \mathrm{kg}$ and oxygen at $2 \mathrm{~L} / \mathrm{min}$, with improvements shown in swallowing, standing-up by herself and ambulation with walker assistance. She was referred to the oncology department for evaluation and follow-up. A sample was sent to a specialized laboratory for determination of antibodies against voltage-gated calcium channels (VGCC) and antibodies against acetylcholine receptors. The results were received 15 days later and showed VGCC $85 \mathrm{pmol} / \mathrm{L}$ (normal value is less than $20 \mathrm{pmol} / \mathrm{L}$ ) and anti-acetylcholine receptor antibodies negative results, whereby the diagnosis was confirmed.

\section{Discussion}

In the case in question, a family history of two cancer varieties, together with manifestations of muscular fatigue initially in the pelvic girdle, hyporeflexia and neurovegetative manifestations, such as dry mouth and constipation, as well as an important body weight loss, suggested the possibility of malignancy, supported by hypercalcemia with normal parathyroid hormone, which in turn led to suspect that the muscular manifestations could correspond to LES. Imaging studies corroborated the presence of neoplasm (even without its origin being determined) with involvement of the central nervous system, the liver and kidney, in addition to electrophysiology test supporting the presence of LES.

LES is an autoimmune neuromuscular transmission presynaptic disorder characterized by muscle weakness and neurovegetative dysfunction. It is often associated with small cell lung cancer. The first reported case belongs to Anderson, et al. ${ }^{5}$ in 1953, and, subsequently, Lambert, Eaton and Rooke, in 1957, reported a series of six patients with defective neuromuscular transmission associated with neoplasm and described the clinical and electrophysiological characteristics of the myasthenic syndrome that carries their surnames ${ }^{6}$.

LES worldwide estimated prevalence ${ }^{7}$ ranges from $1 / 250,000$ and $1 / 333,300$. The onset of the disease usually occurs around 40 years of age, but it can occur at any age. It is characterized by a clinical triad that consists of proximal muscle weakness, neurovegetative disorders and decreased tendon reflexes ${ }^{8}$ (all present in this case). Pharyngeal muscles are involved in LES only in 7\% of patients, with presence of dysphagia $^{8}$ (as in this case). Neoplasms, mainly small cell lung carcinoma, are present in $50-60 \%$ of LES cases. It can be associated with cerebellar ataxia, where it is usually accompanied by small cell lung carcinoma. Up to $90 \%$ of patients with LES have immunoglobulin G-type antibodies against P/Q1-type voltage-regulated calcium channe ${ }^{9}$; dysfunction or reduction in the amounts of these channels inhibits the release of acetylcholine from the presynaptic terminal plate, which causes a decrease in neuromuscular transmission and subsequent muscle weakness. Anti-VGCC antibodies are found in almost $100 \%$ of LES cases, and this does not differ between paraneoplastic and non-paraneoplastic forms. On the other hand, an association between LES, neoplastic or not, and the major histocompatibility antigen HLA-B8 is 

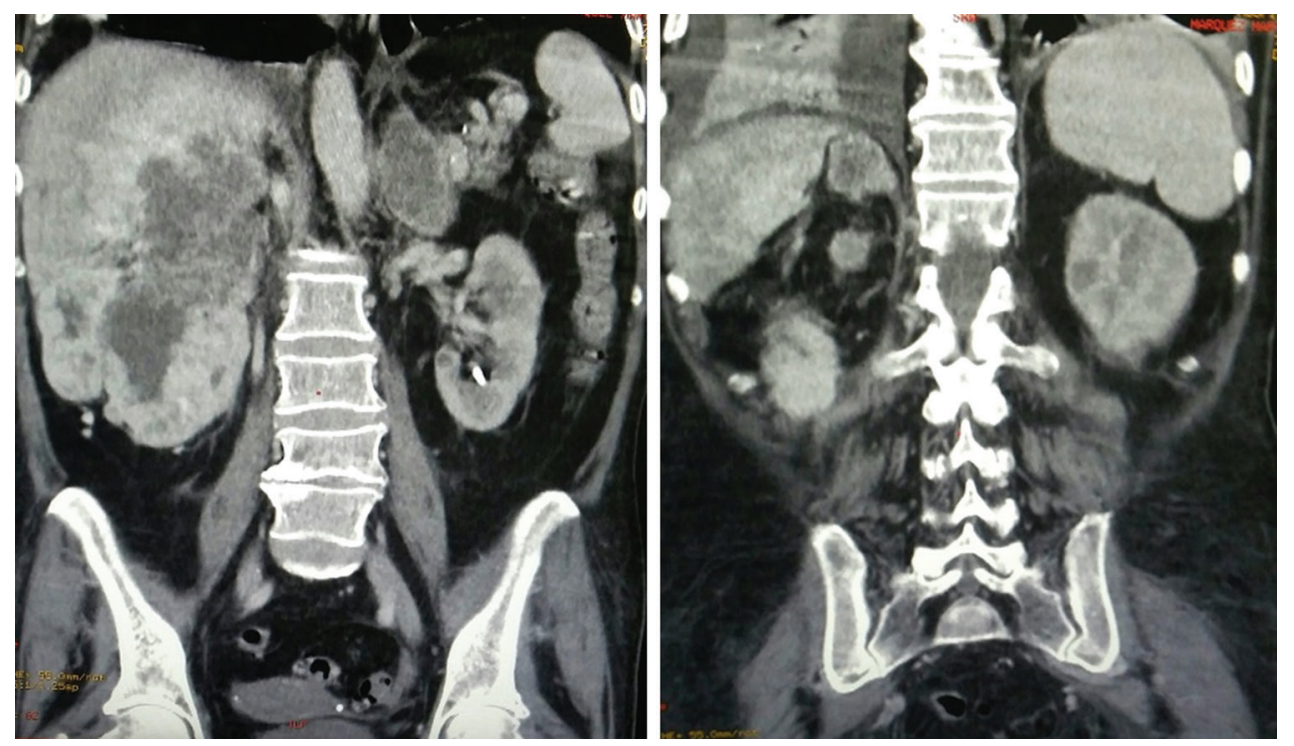

Figure 3. Tomographic images in coronal section, showing a tumor lesion on the upper pole of the right kidney, with $11.2 \times 10.8 \mathrm{~cm}$ in dimension, heterogeneous appearance with hypodense zones, in contact with the liver right lobe, which shows tumor infiltration. The left adrenal gland measures $4.1 \times 3.8 \mathrm{~cm}$, and is hypodense, and nodular in appearance.

mentioned, which is stronger with the non-neoplastic form. Currently, a serum antibody, called $\mathrm{SOX} 1^{10}$, is described in LES and small cell lung carcinoma, which is present in $64 \%$ of cases, and has a specificity of $95 \%$ and a moderate sensitivity of $65 \%$.

In addition to the classical clinical triad (although not always are all three symptoms present), LES diagnosis is based on VGCC antibodies detection by radioimmunoprecipitation assays, as well as on typical abnormalities on repetitive nerve stimulation test ${ }^{11}$, which are characterized by low amplitude compound muscle action potential, in addition to a gradual decrease with low-frequency electrical stimulation, which is inverted with action potential amplitude increase upon high-frequency electrical stimulation or after mild exercise (post-exercise facilitation). Single fiber electromyography can confirm a neuromuscular junction disorder, but it is nonspecific. LES diagnosis almost invariably precedes the discovery of a small cell lung carcinoma; however, it can be associated with other neoplasms, such as lymphoproliferative disorders, breast, colon, stomach, gallbladder, kidney and bladder cancer, adenocarcinoma of the lung, pancreas and prostate, as well as intrathoracic carcinoid neoplasms. Patients with myasthenic syndrome, simultaneously, have an autoimmune disease in about $25-45 \%$ of cases, with organ-specific autoantibodies present. Prevalence of these autoantibodies is higher in the absence of an underlying carcinoma ${ }^{12}$. Clinically and serologically, $30 \%$ of cases occur without an identifiable tumor. The recognition of a classical PNS associated with a single antibody is more an exception than a rule.
Differential diagnosis should include myasthenia gravis, inclusion body myositis, Guillain-Barré syndrome, amyotrophic lateral sclerosis, lumbar canal stenosis, early phase Parkinson's disease and lower-body Parkinsonism.

Management should first consider treatment of the neoplasm, should there be any; this way, weakness may improve after effective cancer therapy. There is no curative treatment for LES, and its management is essentially symptomatic ${ }^{13}$. This includes 3,4-diaminopyridine phosphate, whose mechanism of action involves a selective blockage of potassium channels in the presynaptic membrane, seeking presynaptic action potential longer duration by increasing the release of acetylcholine from the cholinergic and adrenergic terminal. Clinically, 3,4-diaminopyridine decreases muscle weakness and autonomic dysfunction symptoms in up to $85 \%$ of patients. If symptomatic treatment is insufficient, immunosuppressive therapy with prednisone, either alone or in combination with azathioprine, can produce long-term disease control. Plasmapheresis and administration of high doses of intravenous immunoglobulins have a short-term effect. Monoclonal antibodies, such as rituximab ${ }^{14}$, have started being used with apparently promising results. It is essential for an effective treatment against any tumor present to be implemented, both to control the malignancy and to improve LES clinical symptoms. In general, LES responds well to symptomatic and immunosuppressive treatments. However, it can affect patients' daily activities and quality of life. Life expectancy depends on the presence of lung cancer. Without cancer, life 
expectancy is considered to be normal ${ }^{15}$. Since small cell lung carcinoma is a very aggressive cancer, the prognosis of patients with LES and small cell lung carcinoma is usually poor. Mean survival ranges from 17 to 24 months, although the rate of patients with long-term remission or with a cure is approximately $20 \%$, in comparison with less than $2 \%$ for patients with small cell lung carcinoma without SLE.

\section{Conclusions}

This is the case of a female patient with metastatic cancer, newly diagnosed with PNS and LES, who remained hospitalized for 12 days and showed improvement, but owing to the dissemination characteristics of her cancer, she has a poor short-term prognosis.

\section{Ethical responsibilities}

Protection of people and animals. The authors declare that no experiments have been conducted on humans or animals for this research.

Confidentiality of data. The authors declare having followed the protocols of their work center on the publication of patient data.

Right to privacy and informed consent. The authors have obtained informed consent from the patients and/or subjects referred to in the article. This document is in possession of the corresponding author.

\section{Funding}

The authors declare not having received any type of financing.

\section{Conflict of interests}

The authors declare there are no conflicts of interests.

\section{References}

1. Auche M. Des nevrites peripheriques chez les cancereux. Rev Med. 1890;10:785-807.

2. Grausa F, Dalmaua J. Paraneoplastic neurological syndromes Curr Opin Neurol. 2012;25:795-801.

3. Höftberger R, Rosenfeld MR, Dalmau J. Update on neurological paraneoplastic syndromes. Curr Opin Oncol. 2015;27:489-95.

4. Braik T, Evans AT, Telfer M, McDunn S. Paraneoplastic neurological syndromes: unusual presentations of cancer. A practical review. Am J Med Sci. 2010;340:301-8.

5. Anderson HJ, Churchill DH, Richardson AT. Bronchial neoplasm with myasthenia, prolonged apnea after administration of succinylcholine. Lancet. 1953;265:1291-3.

6. Eaton LM, Lambert EH. Electromyography and electrical stimulation of nerves in disease of the motor unit: observations on a myasthenic syndrome associated with malignant tumors. JAMA. 1957;163:1117-24.

7. Wirtz PW, Nijnuis MG, Sotodeh M, et al. The epidemiology of myasthenia gravis, Lambert-Eaton myasthenic syndrome and their associated tumours in the northern part of the province of South Holland. J Neurol. 2003;250:698-701.

8. Fernández-Torrón R, Arcocha J, López-Picazo JM, et al. Isolated dysphagia due to paraneoplastic myasthenic syndrome with anti-P/Q-type voltage-gated calcium-channel and anti-acetylcholine receptor antibodies. Neuromuscul Disord. 2011;21:126-8.

9. Motomura $\mathrm{M}$, Lang $\mathrm{B}$, Johnston I, et al. Incidence of serum anti-P/Qtype and anti-N-type calcium channel autoantibodies in the Lambert-Eaton myasthenic syndrome. J Neurol Sci. 1997;147:35-42.

10. Titulaer MJ, Klooster R, Potman M, et al. SOX antibodies in small-cell lung cancer and Lambert-Eaton myasthenic syndrome: frequency and relation with survival. J Clin Oncol. 2009;27:4260-7.

11. AAEM Quality Assurance Committee. Practice parameter for repetitive nerve stimulation and single fiber EMG evaluation of adults with suspected myasthenia gravis or Lambert-Eaton myasthenic syndrome: summary statement. Muscle Nerve. 2001;24:1236-8.

12. Pellkofer HL, Armbruster L, Krumbholz M, et al. Lambert-Eaton myasthenic syndrome differential reactivity of tumor versus non-tumor patients to subunits of the voltage-gated calcium channel. J Neuroimmunol. 2008; 204:136-9.

13. Skeie GO, Apostolski S, Evoli A, et al. Guidelines for treatment of autoimmune neuromuscular transmission disorders. Eur J Neurol. 2010; 17:893-902.

14. Maddison $\mathrm{P}$, McConville J, Farrugia ME, et al. The use of rituximab in myasthenia gravis and Lambert-Eaton myasthenic syndrome. J Neurol Neurosurg Psychiatry. 2011;82:671-3.

15. Wirtz PW, Smallegaange TM, Wintzen AR, et al. Difference in clinical features between the Lambert-Eaton myasthenic syndrome with and without cancer: an analysis of 227 published cases. J Neurol Neurosurg Psychiatry. 2002;104:359-63. 